\title{
Non-Inferential Aspects of Ad Hominem and Ad Baculum
}

\author{
Katarzyna Budzynska $\cdot$ Maciej Witek
}

Published online: 19 July 2014

(C) The Author(s) 2014. This article is published with open access at Springerlink.com

\begin{abstract}
The aim of the paper is to explore the interrelation between persuasion tactics and properties of speech acts. We investigate two types of arguments $a d: a d$ hominem and ad baculum. We show that with both of these tactics, the structures that play a key role are not inferential, but rather ethotic, i.e., related to the speaker's character and trust. We use the concepts of illocutionary force and constitutive conditions related to the character or status of the speaker in order to explain the dynamics of these two techniques. In keeping with the research focus of the Polish School of Argumentation, we examine how the pragmatic and rhetorical aspects of the force of ad hominem and ad baculum arguments exploit trust in the speaker's status to influence the audience's cognition.
\end{abstract}

Keywords Communicative and cognitive structures · Ethos · Trust - Speech acts · Pragmatic force of argument

A comment to this article is available at doi:10.1007/s10503-014-9318-2.

K. Budzynska $(\bowtie)$

Institute of Philosophy and Sociology, Polish Academy of Sciences, ul. Nowy Swiat 72, p. 225,

00-330 Warsaw, Poland

e-mail: budzynska.argdiap@gmail.com

K. Budzynska

School of Computing (Queen Mother Building), University of Dundee, Dundee DD1 4HN,

Scotland, UK

M. Witek

Institute of Philosophy, University of Szczecin, ul. Krakowska 71-79, 71-017 Szczecin, Poland

e-mail: maciej.witek@univ.szczecin.pl 


\section{Introduction}

The paper aims to develop a uniform account of two rhetorical techniques: $a d$ hominem argument (cf. Walton 1998; Załęska 2011) and ad baculum argument ( $c f$. Walton 2000; Cap 2013). We describe them in terms of the illocutionary acts they involve as well as in that of the speaker's ethos, character, deontic status or trust (Aristotle 1991; Braet 1992; Searle 2010; Witek 2013a). It is worth stressing that the concern in this paper is with the structure of ad hominem and ad baculum arguments and not e.g. of their fallaciousness. We further combine formal considerations with pragmatic aspects of communication following the approach characteristic of the research of the Polish School of Argumentation ( $c f$. DebowskaKozlowska 2014; see also Koszowy and Araszkiewicz 2014; Reed and Koszowy 2011 for an overview of this approach).

Our hypothesis is that at least some aspects of the structure of these rhetorical techniques can be best accounted for in terms of illocutionary points and ethotic conditions rather than in terms of premises and conclusions. We also agree that they can be naturally characterised by reference to their perlocutionary goals and consequences. We describe ad hominem and ad baculum techniques as complex rhetoric techniques in order to examine those aspects of their structure, functioning and pragmatic force that can be described and explained within the framework of speech act theory (Austin 1975; Searle 1969) (see also van Eemeren and Grootendorst 1989; Goodwin 2014; Snoeck-Henkemans 2014 for the links between speech acts and argumentation).

\section{Ad hominem Technique}

Standard approaches that investigate communicative and cognitive structures typically treat ad hominem, AH, as an inferential structure (see e.g., Walton 1998). We claim that models which limit the representation of messages solely to their logos-based structure in this way are not sufficient for capturing all the aspects of AH technique (Sect. 2.1). If we want to directly describe ad hominem as personal attack (Walton 1998, p. 23), we need an independent ethotic component to be included, i.e., a component related to the character of the speaker and one which can occur without the presence of any inferential structure. We propose an extension to standard models that incorporates such a component using elements of speech act theory (Sect. 2.2). As a result, the new model allows us to explain what exactly is attacked by ad hominem technique (Sect. 2.3).

\subsection{Standard Approaches to Ad Hominem Argument}

Different types of ad hominem have been identified and there is definitely no agreement on what really constitutes AH arguments (see e.g., Walton 1998 for an excellent overview). In this paper, we focus on a subclass of ad hominem techniques understood as personal attack (i.e., in which the proponent attacks the person of his opponent rather than the content of what the opponent has said) ignoring the other 
important subclass introduced by Locke, i.e., arguments from the opponent's commitments (Walton 1998, pp. 21-23). Moreover, we limit our considerations to the most basic type of $\mathrm{AH}$ personal attack, and start from the inferential account proposed in (Walton 1998, p. 112), in which "bad person" is interpreted very broadly, i.e., as the speaker's deficiency with respect to, e.g., his veracity, prudence, perception, cognitive skills, morals; (Walton 1998, pp. 250-251):

\section{GENERIC AH ARGUMENT SCHEME}

$i$ is a bad person.

Therefore, $i$ 's argument $A$ should not be accepted.

When considering inferential models, we can ask where the personal attack (i.e., an attack on ethos) is expressed in the communicative and cognitive structure, or in other words: whether this attack is really targeted at ethos. Consider a very simple example of $\mathrm{AH}$ used in the dialogical context:

(1) a. Bob said, $p$

b. Wilma said, Why $p$ ?

c. Bob said, $q$

d. Wilma said, You know nothing about it!

Using Walton's account, two inferential structures can be identified in (1). The first one, $A 1$, is delivered by Bob, and consists of the conclusion $p$ uttered in (1-a) supported by the premise $q$ uttered in (1-c). The second inferential structure, $A 2$, will be identified in this dialogue, if we assume that Wilma's move (1-d) is a generic $\mathrm{AH}$ argument. It is not clear what exactly Wilma's critique refers to: Bob's whole argument $A 1$, the premise $q$, or maybe the conclusion $p$. Let us choose the second interpretation for the sake of simplicity, but the same can be shown for any of them. ${ }^{1}$ We also assume that "Bob knows nothing about it" constitutes an instance of the AH premise "Bob is a bad person". Following Walton's AH scheme, the utterance (1-c) or (1-d) should be reconstructed as $A 2$ in Table 1.

One advantage of such a representation is that it uses the relatively well-elaborated concepts from traditional logic, i.e., it allows us to explain the AH technique in terms of inference and contradiction. That is, we can say that when the speaker uses the AH technique, then she infers that Bob's argument cannot be accepted (A2's conclusion) using Bob's defective ethos (A2's premise), what in turn contradicts the acceptance of $A 1$ 's premise and as a result undercuts Bob's argument for $p .^{2}$

Now let us return to the question we raised above: Where exactly is the attack on ethos represented in this model? It can be said that it is captured by the contradiction (such as the contradiction between A2's conclusion and the acceptance of $A 1$ 's premise in Table 1), however, observe that this attack does not aim at the opponent's character. The conclusion of the AH argument is attacking (contradicting) what Bob said, i.e., q, rather than Bob's character itself. We could say that the

\footnotetext{
1 In fact, it is irrelevant whether we reconstruct $\mathrm{AH}$ as related to $q$, to $p$, or to $A 1$, even though the last interpretation presents more serious technical challenges.

2 The formal representation would not, however, be trivial, for the contradiction would not be between $q$ and $\neg q$, but between modal statements " $q$ should be accepted" and " $q$ should not be accepted".
} 
Table 1 The reconstruction of inferences in the dialogue (1) according to Walton's model

\begin{tabular}{lll}
\hline & Argument $A 1$ & Argument $A 2$ \\
\hline Conclusion & $p$ & $q$ should not be accepted \\
Premise & $q$ & Bob is a bad person \\
\hline
\end{tabular}

communicative technique described by Walton does not directly describe an attack on ethos, but rather the attack on the opponent's logos, while having its "roots" in the opponent's defective ethos ("roots" rather than "target"). In other words, the attack aims at the propositional content of the opponent's utterance and this attack is represented by the contradiction between (the acceptance of) this content and the AH's conclusion. Thus, the opponent's character plays a role here not as an aim of the attack, but as its justification.

\subsection{Ad Hominem as an Attack on Ethos}

The question we want to explore in this section is whether it is necessary to interpret Wilma's communicative and cognitive behaviour in (1-d) as the attempt to prove why she does not accept $q$. We claim that an alternative and more straightforward formal interpretation of her intentions is possible. That is, we could understand this utterance as her asserting that Bob's ethos is defective, i.e., expressing distrust in his ethos, with respect to $q$ as much as she could assert that he is tall, short, handsome, ugly, blond, dark and so on. Additionally, by virtue of this specific assertion being a response to Bob's assertion that $q$ - she establishes another illocutionary force of ad hominem speech act which attacks the ethotic condition on Bob's act (1-c), i.e., the ethotic condition on Bob's asserting $q$.

In other words, if we want to represent ad hominem explicitly as an attack on ethos (rather than a support of an attack on the opponent's logos), the challenge is to introduce the component representing the speaker's character directly in the model of the AH structure (Budzynska 2010). We claim that such an ethotic component can be defined in terms of the elements of speech act theory. ${ }^{3}$ We use Inference Anchoring Theory, IAT, (Budzynska and Reed 2011) to express inferential, dialogical and illocutionary structures, and relations amongst them. Within this framework, the dialogical move (1-a) is interpreted as the locution linked with its propositional content $p$ through the illocutionary connection associated with the specific illocutionary force of (1-a), i.e., the illocutionary connection of asserting. Amongst the felicity conditions of performing the speech act of asserting, there are conditions related to the character of the speaker, i.e., in the case of (1-a), ethotic conditions on Bob's character such as his believing $p .^{4}$

\footnotetext{
${ }^{3}$ A speech act $F(A)$ is a communicative action of uttering the propositional content $p$ with the illocutionary force $F$ of asserting, questioning, arguing, promising, requesting and so on. Felicity (constitutive) conditions determine what a speech act has to satisfy in order to have its illocutionary force properly recognised (Searle 1969).

${ }^{4}$ The explanatory merits of such a model was demonstrated on the example of ethotic circularity of selfreferential utterances such as: Bob said, I am credible (Budzynska 2013).
} 
Such ethotic conditions hold for each assertive connection including also (1-c) (see Table 2). This means that this utterance will be a successful assertion about $q$ as long as we assume that Bob's character is not in some way defective. And this is exactly what, according to IAT, Wilma's tries to attack in the next move. The locution in (1-d) is linked with its propositional content "Bob knows nothing about $q$ " again via an assertive illocutionary connection (which has its own ethotic conditions, but this time related not to Bob's but to Wilma's character, see the ethotic condition on (1-d) in Table 2). ${ }^{5}$ Still the assertion (1-d) does not only convey some information about Bob (i.e., that he does not know anything about $q$ ), but by virtue of its being the response to Bob's assertion (1-c), it has also the illocutionary force of ad hominem act which establishes a relation of conflict (attack) between (1-c)'s ethotic condition and (1-d)'s propositional content.

According to this account, the ad hominem technique is a speech act that has a relational content (between the ethotic condition "Bob has non-defective ethos" in (1-c) and the content "Bob knows nothing about $q$ " in (1-d)). That is, AH is structurally different from standard speech acts like assertion or question which have a text unit as a propositional content. In particular, we cannot treat $\mathrm{AH}$ as having the content: "Bob knows nothing about it", since this proposition on its own does not constitute the AH attack. If Wilma walks into a room and says, "Bob is not very smart", then this utterance will by itself not be ad hominem attack, but just some description of Bob. It is by virtue of it being a response to something that Bob previously said that we are allowed to interpret Wilma's statement as an attempt to discredit what Bob is saying by pointing at some of his ethotic deficiencies and her distrust, i.e., as the rhetoric technique of AH personal attack.

\subsection{What Specifically is Attacked by AH?}

In this section we propose to account for the functioning of ad hominem acts within the conceptual framework of speech act theory in a more detailed manner. Following Gazdar, we take a speech act to be "a function from contexts into contexts." (Gazdar 1981). In other words, speech acts are context-changing social actions ( $c f$. Sbisà 2002, p. 421; Debowska 2007, pp. 308-309). In particular, to make a felicitous illocutionary act is to change or update the context of its production by bringing about certain normative facts. To make a binding promise in uttering "I will do $A$ ", for example, is to turn a context in which the speaker is not committed to perform action $A$ into a context in which he is committed to do $A$; by analogy, the issuing of a felicitous order in uttering "Do $A$ !" produces the hearer's obligation to do $A$, and the performing of a felicitous assertion that $p$ creates the speaker's commitment to the truth the proposition that $p$ as well as the hearer's right to accommodate the proposition into his belief system. ${ }^{6}$

In some cases, however, one can bring about certain normative facts indirectly, by means of a mechanism akin to what Lewis called presupposition accommodation

\footnotetext{
5 Wilma's ethos can be then (counter-)attacked in the next move by Bob, $c f$. (Budzynska and Reed 2012).

${ }^{6}$ It is worth to stress that in this paper we adopt the institutionalist approach to the study of speech acts; for a discussion of this approach and its alternatives (see Witek 2013b).
} 
Table 2 The reconstruction of AH technique in (1) as an attack on the opponent's ethos

\begin{tabular}{lll}
\hline & Assertion in (1-c) & Assertion in (1-d) \\
\hline Content & $q$ & Bob knows nothing about $q$ \\
Ethotic condition & Bob's ethos & Wilma's ethos \\
\hline
\end{tabular}

(Lewis 1979) (cf. Witek 2013a). The point is that the felicity of an illocutionary act "presupposes a lot of things" (Austin 1975, p. 51): the felicity of an order presupposes (in Austin's sense) that the speaker stands in an appropriate authority relation to his audience, the felicity of an assertion that $p$ presupposes that the speaker knows something about the domain to which $p$ belongs, the felicity of a promise made in uttering "I will do $A$ " presuppose that the speaker is able to do $A$, and so on. We will assume that the felicity of an illocutionary act presupposes in Austin's sense that the speaker has an appropriate non-defective character or, as Searle puts it, an appropriate status function that carries certain deontic powers: "rights, duties, obligations, requirements, permissions, authorizations, entitlements, and so on" (Searle 2010, p. 9). In some cases the speaker's status, ethos and trust can be modified indirectly by the mechanism of Austinian presupposition accommodation: a rule-governed context-adjusting process whose function is to repair the context of an utterance to make the utterance a felicitous performance of a statement, order, promise, and so on (see Witek 2013a for a detailed discussion of this topic).

Imagine, for example, that Alice, Tom and a few other people have survived a plane crash and found themselves on a desert island. Alice says to Tom: "Go and pick up wood" and Tom complies with what he is told. In other words, Tom takes the utterance to be a felicitous order. ${ }^{7}$ One of the ethotic conditions under which the speaker can perform a binding directive act is that she stands in an appropriate authority relation to her audience. Therefore, the felicity of Alice's order made in uttering sentence "Go and pick up woods" presupposes in Austin's sense that it is part of the context that she has an appropriate status, i.e., the status that carries, among other things, her deontic power to issue Tom binding commands. Observe, however, that this requirement is not satisfied prior to time $t$ at which the utterance under discussion is produced. To note this, however, is not to say that Alice's utterance is an infelicitous order. If Tom complies with what he is told, he takes the utterance as a binding command. What is more, in doing this he repairs the context against which Alice's utterance is to be evaluated or, in other words, accommodates the Austinian presupposition of Alice's directive act. As the corollary of this, Alice's ethotic status has been modified indirectly by the mechanism of Austinian presupposition accommodation.

Let us go back to example (1). Observe that in making the utterance reported in (1-c) Bob attempts to perform a binding or felicitous assertion that $q$. The felicity of

\footnotetext{
${ }^{7}$ One of the preparatory conditions for making a binding order in uttering "Do A!" is that it is not obvious to both the speaker and the hearer that the hearer will do $A$ in the normal course of events of his own record (see Searle 1969, p. 66). That's why Alice saying to Tom "Breath in!" cannot be said to be making an order, and Tom who keeps breathing cannot be said to be complying with what he is told.
} 
such an assertion presupposes in Austin's sense that he has an appropriate ethotic status (and as a result - that the hearer trusts that he possesses such a status); in particular, it presupposes that Bob knows something about the domain to which $q$ belongs. From the speech act theoretical point of view, the function of utterance (1-c) — provided it is a successful assertion-is to update Bob and Wilma's common ground (in particular, to update the common ground representations of their normative or deontic statuses). Note, however, that it can be updated both (1) directly by accommodating the explicit content of utterance (1-c) and, at the same time, (2) indirectly by accommodating the Austinian presupposition of the felicity of Bob's assertion.

Now we are in a position to explain the mechanism underlying the ad hominem techniques: in uttering "You know nothing about it", Wilma explicitly and directly refuses to (indirectly) accommodate the Austinian presupposition of Bob's act and, by the same token, implicitly and indirectly refuses to (directly) accommodate the explicit content of his act.

\section{Ad Baculum Technique}

In this section, we show that not only inference (as standard models assume, see Sect. 3.1), but also ethotic conditions on illocutionary acts and pragmatic forces play a crucial role in the structure of ad baculum technique, AB. We take ad baculum to be a rhetoric technique involving two illocutionary acts: a directive act and a commissive act (Sect. 3.3). We also claim that the threat, which according to Walton (2000)'s account is a key component of the AB technique, can be best explained here not as perlocutionary, but rather illocutionary, act (Sect. 3.2).

\subsection{Standard Approaches to Ad Baculum Argument}

Standard approaches disagree on the details of ad baculum structure, but most of them agree that it involves inference. There is also a lot of controversy in the literature about whether the $\mathrm{AB}$ technique is an appeal to force, threat, fear, or to some combination of the above (see Walton 2000 for a comprehensive survey). In this paper we do not address the question of which of these approaches should be adopted to best describe ad baculum, but we discuss an alternative model to the inferential ones using the example of AB model proposed in (Walton 2000, 2008).

Walton's model assumes that threat appeal has an inferential structure of argument from negative consequences (Walton 2000, p. 140). Ad baculum argument refers additionally to the essential condition of the speech act of making a threat: "the speaker is undertaking to see to it that the event will occur unless the hearer carries out the particular action designated by the speaker" (Walton 2000, p. 128). In other words, the speaker is not only saying that the undesirable event $B$ will happen (as in argument from negative consequences), but he also threatens that it will be him (the speaker) who will make it happen unless the hearer will bring about $A$ (Walton 2000, p. 140): 
Table 3 The reconstruction of inferences in ad baculum in (2) according to Walton's model

\begin{tabular}{ll}
\hline & Argument A3 \\
\hline Conclusion & You should give me money \\
Premise $_{1}$ & Either you give me money or I will take your life \\
Premise $_{2}$ & Taking your life is a very bad outcome from your point of view \\
\hline
\end{tabular}

ARGUMENT SCHEME FROM DISJUNCTIVE $A D$ BACULUM THREAT ${ }^{8}$

Either you bring about $A$ or I undertake to see to it that $B$ will occur.

$B$ is a very bad outcome, from your point of view.

Therefore, you should bring about $A$.

Consider the following example cited in (Walton 2000, p. 37):

(2) The robber said, Your money or your life!

The ad baculum technique used in this case could be reconstructed according to Walton's model as it is proposed in Table 3:

Our aim in the paper is not to analyse whether this inferential model correctly represents ad baculum, or how to use it to evaluate the fallacious instances of the $\mathrm{AB}$ technique. We rather use it as a starting point for focusing on another aspect of the $\mathrm{AB}$ technique, i.e., following the idea that the use of a threat is central for ad baculum, we want to ask two questions: (1) are there any illocutionary points associated with threats, or are there only perlocutionary goals of persuading a threatened person?; and (2) are there any other communicative goals of using a threat besides an attempt to establish an inference which justifies the actions that the threatened person should undertake? We will address these issues in the two following sections.

\subsection{Making a Threat as an Illocutionary Act}

The main idea behind our non-inferential approach to the ad baculum technique is that $\mathrm{AB}$ is a complex rhetoric technique which involves two ancillary and complementary illocutionary acts, one of which is a directive (an order, command, and so on) and the other is a commissive act of making a threat. Before we get into the details, however, let us justify our assumption that making a threat is an illocutionary act, i.e., the act of bringing about normative states of affairs such as commitments and entitlements (Sbisà 2002; Witek 2013b), rather than a perlocutionary act, i.e., the act of producing "certain consequential effects upon the feelings, thoughts, or actions of the audience" (Austin 1975, p. 101).

\footnotetext{
${ }^{8}$ Walton points out that the typical form of a threat is either a conditional: "If you (the hearer) don't carry out this action, then some bad event will happen to you", or its formal equivalent of disjunction: "Either you (the hearer) carry out this action, or some bad event will happen to you" (Walton 2000, p. $111,126)$. As a result, he distinguishes two types of the $A B$ arguments which differ with respect to the form of its first premise (see Walton 2000, p. 142 for more details).
} 
For some scholars the main reason against regarding threats as illocutionary rather than perlocutionary acts seems to be the lack of a conventional formula or verbal pattern that could be treated as indicating the illocutionary force of making a threat (see Walton 2000, pp. 101-128). For example, there is no performative prefix of the form "I threaten you with..." with the help of which the speaker could make explicit his intention to make a threat. Discussing the difference between the illocutionary and the perlocutionary act, Austin observes that "the former (...) could be made explicit by the performative formula; but the latter could not. Thus we can say 'I argue that' or 'I warn you that', but cannot say 'I convince you' or 'I alarm you that", (Austin 1975, pp. 103-104). Following this line of argument one can observe that it is unnatural to say "I threaten you with..." and conclude that making a threat, like convincing and alarming, is a perlocutionary act.

In our view, however, the performative formula criterion, though helpful, is not decisive. More specifically, it is true that to justify the opinion that there exists an illocutionary act type of $F$-ing it suffices to demonstrate that the members of some community use the prefix "I (hereby) $F$..."; the existence of such a prefix, however, is not the necessary condition for there being the illocutionary act type of $F$-ing. As Austin noted, "from the point of view of the evolution of language, the explicit performative must be a later development than certain more primary utterances" (Austin 1975, p. 71). In other words, the acts of making a threat can function as primitive illocutionary acts whose force cannot be made explicit by means of an appropriate performative prefix. But it can be made explicit with the help of what Strawson (1964, p. 451) called a force-elucidating comment. For example, after saying "I will talk to your father about your bad behaviour" one can add "That was a threat" thereby making it clear what the force of one's act is. According to Strawson, it is better to view such a case not as one "in which we have two utterances, one commenting on the other, but as a case of a single unitary act" (Strawson 1964, p. 451). In our view, one can take such quasi-comments to be evolutionary predecessors of many explicit performative formulas.

Let us acknowledge, therefore, that the verb "to threaten" cannot be used in the context of an appropriate explicit performative prefix of the form "I (hereby) $F$...". 9 Apart from this, however, it behaves linguistically as other illocutionary verbs. For example, it can be used in the "in doing" constructions whose function is to report illocutionary acts, but not in the "by doing" constructions that are normally used to report perlocutionary acts. According to Austin, for example, it is natural to say "In saying I would shoot him I was threatening him" and "By saying I would shoot him I alarmed him." (Austin 1975, p. 122). What is more, the verb "to threaten", like other illocutionary verbs, has its perlocutionary counterpart: one can argue and thereby convince one's audience, one can warn and thereby alert one's interlocutor, and one can threaten and thereby intimidate one's audience.

So far we considered a possible argument against regarding threats as illocutionary acts and argued that it is insufficient and inconclusive. Now we would like to make a positive case for the claim that threats form an illocutionary

\footnotetext{
${ }^{9}$ It is worth noticing, however, that according to (Austin 1975, p. 131) we "can use the performative 'I threaten you with' but not 'I intimidate you by'."
} 
act type. The main idea is that the act of making a threat, like other illocutionary acts, can be analysed in terms of felicity conditions for the non-defective performance of threats. According to our analysis-which is modelled on Searle's analysis of promising (Searle 1969, pp. 57-64) and Walton's analysis of making a threat (Walton 2000, 2008) - in uttering a sentence of the form "I will do $A$ " in the presence of a hearer $H$, a speaker $S$ non-defectively and literally makes a threat only if:

\section{- Preparatory Conditions:}

(1) $S$ 's status - no matter whether it derives from $S$ 's position in an institution or $S$ 's physical properties - carries the power or ability to do $A$.

(2) $H$ would prefer $S$ 's not doing $A$ to $S$ 's doing $A$, and $S$ believes $H$ would prefer $S$ 's not doing $A$ to $S$ 's doing $A$.

(3) It is not obvious to both $S$ and $H$ that $A$ will occur in the normal course of events without $S$ 's intervention.

- Sincerity Condition: (4) $S$ intends to do $A$.

- Essential Condition: (5) $S$ intends that the utterance of "I will do $A$ " places $S$ 's under an obligation to do $A$.

Following (Walton 2008, pp. 121-122), therefore, we assume that threats, like promises, are commissive acts whose illocutionary point-specified in the essential condition - is to undertake an obligation to perform a certain action; the only difference lies in the fact that the action in question, unlike the promised one, is something that the hearer would like to avoid or, more accurately, something that he regards as bad or undesirable (we do not, however, claim that the act of threatening is a subspecies of promising, see (Walton 2000, pp. 109-111) for the discussion). It is also worth stressing that condition (1) imposes certain ethotic constraints on the speaker: one cannot make a binding act of making a threat in uttering "I will do $A$ " unless one is able to do $A$. In other words, one's ability to do $A-$ no matter whether it results from one's institutional status or one's non-institutional properties-is presupposed in Austin's sense by the felicity of one's act of making a threat and as such constitutes one's ethos.

\subsection{Ad Baculum as an Illocutionary Act}

In this section we develop an account according to which the rhetorical technique of ad baculum involves the act of making an order and the act of making a threat. Consider again the robber's example (2) and also the following one:

(3) The professor said, If you don't hand in your paper on time, I will give you a failing grade in the course.

According to standard models-developed, e.g., by Walton-the structure of the utterances (2) and (3) is inferential and as such involves premises and conclusions (see Sect. 3.1).

In our view, however, this rhetoric technique has an important pragmatic component that is not captured by the inferential approaches. We claim that this 
communicative and cognitive tactic of ad baculum is an illocutionary complex act that can be analysed into two closely related components: (1) the directive act that puts the respondent under the obligation to bring about $A$, and (2) the commissive act that produces the proponent's commitment to do $B$ if the respondent fails to bring about $A$.

Our hypothesis is, then, that sentences (2) and (3) can be used to make the illocutionary $\mathrm{AB}$ act that involves directive and commissive aspects. Roughly speaking, the job of the directive part of an ad baculum act is to create the respondent's obligation to do $A$, whereas the function of its commissive part is to indicate-via the mechanism involving Austinian presuppositions (see Sect. 2.3) the proponent's status function. Recall that every status function carries certain deontic powers: "rights, duties, obligations, requirements, permissions, authorizations, entitlements, and so on" (Searle 2010, p. 9). In the case of AB, the status function indicated by its commissive element carries, among other things, the proponent's power to give the respondent binding orders with respect to $A$. The proposition "you (the respondent) should bring about $A$ ", which constitutes the conclusion in the inferential approach, here becomes part of the common ground among the participants in a dialogue in virtue of the directive act. This act is made by the proponent whose power to make binding directive acts with respect to $A$ is indicated or even strengthened by his corresponding commissive act. What glues these two acts together and makes them two complementary aspects of one illocutionary act of ad baculum is the fact that they presuppose in Austin's sense the same status function or ethotic conditions imposed on the proponent.

In short, according to our model the speech acts made in uttering sentences (2) and (3) are complex rhetoric techniques of ad baculum within which one can distinguish two complementary aspects: a directive act made in uttering "Do A!", and a threat made in uttering "I will do $B$ ". This structure is made explicit by the following paraphrases:

$(2)^{\prime}$ The robber said, Give me your money or I will shoot you!

$(3)^{\prime}$ The professor said, Hand in your paper on time or I will give you a failing grade in the course.

In our view, the illocutionary point of the ad baculum technique involves two aspects: (1) making the respondent committed to do $A$ by (2) getting him to recognize the proponent's power to make binding orders with respect to $A$. Part (1) of the ad baculum illocutionary point is brought about by the directive act, whereas part (2) is created by the complementary or ancillary act of making a threat. What glues these two acts together is the fact that $(a)$ the ethotic constraint on one's making a binding order to do $A$ and $(b)$ the ethotic conditions on one's making a binding threat to do $B$ are carried by the same status function that can be described as one's standing in a certain power relation to one's audience. For example, $(a)$ the robber's power to make felicitous orders in uttering "Give me your money" and (b) his power to make a binding threat in uttering "I will shoot you" are both derived from his status that results from his having a gun in his hand (see Table 4). Analogously, (a) the professor's power to make a binding directive act in uttering 
Table 4 The reconstruction of $\mathrm{AB}$ technique in (2)

\begin{tabular}{lll}
\hline & Directive act in (2) & Commissive act in (2) \\
\hline Content & Give me your money & I will shoot you \\
Ethotic condition & Robber's ethos & Robber's ethos \\
\hline
\end{tabular}

"Hand in your paper on time" and $(b)$ his power to make a felicitous threat in uttering "I will give you a failing grade in the course" are carried by his institutional status as the student's teacher.

Recall that our aim in this section is not to reject the inferential account of the AB technique, but to develop an alternative model and use it to explain those pragmatic and rhetorical aspects of ad baculum that can hardly be accounted for in terms of premises and conclusions. According to our model, then, the proposition "The respondent should do $A$ " (i.e., the conclusion in the inferential approach) is contributed to the common ground by the felicitous act of ad baculum. The job of the threat (considered as a premise in the inferential approach) is to indicate or communicate the proponent's power to make the binding act. To illustrate our point, let us consider a robber who has a gun in his hand and says to his victim:

(4) The robber said, Your money.

According to Searle-from whom we borrow this example - the robber in uttering (4) performs a binding order. What makes the utterance of (4) a binding order is the fact that the robber stands in a power relation to the victim or, in other words, that he is endowed with a certain status function: the robber, "in virtue of his possession of a gun, may order as opposed to, e.g., request, entreat, or implore victims to raise their hands. But his status here does not derive from a position within an institution but from his possession of a weapon" (Searle 1979, p. 7). In our view, the function of the threat component of the ad baculum act made in uttering (2) can be likened to that of the gun in the robber's hand: it indicates the robber's status that enables him to make certain binding orders. The only difference lies in the fact that in the case of the act made in uttering (2) the mechanism whereby the status is indicated involves the communicative act of making a threat and its Austinian presuppositions.

\section{Ethos as a Link Between Ad Hominem and Ad Baculum}

The job of attacks on ethos and appeals to threat is to bring about certain changes in the common ground among the participants in a dialogue. To make a felicitous illocutionary act of ad hominem is to update the context with the proposition to the effect that the opponent's alleged or claimed power to make binding acts of a certain type-e.g. assertions, directives, promises, and so on-is explicitly revoked or rejected. A felicitous illocutionary act of ad baculum, in turn, changes a context in which the respondent is not committed to do $A$ into a context into which he should do $A$. Our contention is that the mechanisms that are responsible for bringing about 
such changes are not inferential. In our view, the functioning of ad hominem and ad baculum speech acts can be best captured in terms of the conditions for their felicitous performance-or, more specifically, by reference to the status functions or ethos of the participants in conversation-rather than in that of premises and conclusions.

Our non-inferential model of the $\mathrm{AH}$ and $\mathrm{AB}$ techniques has certain explanatory merits. For example, it provides a uniform and simple explanation of situations into which the proponent's ad baculum is attacked by the respondent with the help of the ad hominem technique. Consider the following talk-exchange:

(5) a. The professor said, Hand in your paper on time,

b. The professor said, or I will give you a failing grade in the course.

c. The student said, The situation has changed: you are not my teacher.

Of course one can account for the above dialogue using the standard inferential models discussed in Sects. 2.1 and 3.1. That is to say, one can reconstruct, first, an inference from the premise introduced in uttering (5-b) to the proposition that the student should hand in his paper on time in (5-a) and, second, a further reasoning that starts with a premise introduced in uttering (5-c) and ends with the conclusion that the professor's words should not be counted as binding ad baculum. In our model, however, we can also say that in uttering (5-b) the professor indicates or communicates - by exploiting the mechanisms of Austinian presuppositions-her status function or ethos that enables her to give the student binding orders or, more specifically, her power to order the student to hand in his paper on time.

By the same token, it is natural to say that in uttering (5-c) the student uses ad hominem to attack the professor's claimed status or, in other words, refuse to accommodate the Austinian presupposition of her ad baculum act by rejecting to trust her ethos. Undoubtedly, it is a matter of dispute which one of these two accounts-i.e., the inferential one or the one in terms of ethotic status-is adequate. Nevertheless, our contention is that the latter is at least an attractive alternative to the former. What makes it attractive, we believe, is that it allows for the possibility that at least in some cases an utterance can change the context of its production in virtue of its illocutionary function rather than in that of its inferential potential, i.e., its potential to introduce certain propositions to reasoning.

\section{Conclusions}

The model proposed in the paper describes the pragmatic aspects (such as illocutionary forces) and rhetoric aspects (such as ethos, status and trust) of the force of ad hominem and ad baculum techniques rather than their inferential aspects emphasised by standard approaches to their structures. We propose to understand $\mathrm{AH}$ as an illocutionary act with pragmatic force of undercutting the opponent's ethos associated with a speech act performed by the opponent at some previous move in a dialogue. Ad baculum is, on the other hand, modelled as an illocutionary complex act involving a directive act that puts the respondent under the obligation to bring about some action, and a commissive act that produces the proponent's 
commitment to do something undesired by the respondent, if he fails to bring about this action. The important ethotic nature of those rhetorical techniques manifests itself in their harmonious coexistence, i.e., after the attempt of imposing on the hearer to trust the power status of the performer of ad baculum, it is natural for the threatened person to response with ad hominem in order to refuse to accept and trust the suggested status.

Acknowledgments We gratefully acknowledge the support of the Polish National Science Center under grants 2011/03/B/HS1/04559 and 2011/03/B/HS1/00917. We would also like to thank Prof. Chris Reed and ARG-tech group for the valuable comments and discussion.

Open Access This article is distributed under the terms of the Creative Commons Attribution License which permits any use, distribution, and reproduction in any medium, provided the original author(s) and the source are credited.

\section{References}

Aristotle. 1991. Rhetoric (translated by G. A. Kennedy). Oxford: Oxford University Press. Austin, J.L. 1975. How to do things with words, 2nd ed. Oxford: Oxford University Press.

Braet, A. 1992. Ethos, pathos and logos in Aristotle's rhetoric: A re-examination. Argumentation 6(3): 307-320.

Budzynska, K. 2010. Argument analysis: Components of interpersonal argumentation. In: Frontiers in Artificial Intelligence and Applications. Proceedings of 3rd International Conference on Computational Models of Argument (COMMA 2010), vol 216, pp. 135-146.

Budzynska, K. 2013. Circularity in ethotic structures. Synthese 190(15): 3185-3207. doi:10.1007/s11229012-0135-6.

Budzynska, K., and C. Reed. 2011. Whence inference? University of Dundee Technical Report.

Budzynska, K., and C. Reed. 2012. The structure of ad hominem dialogues. In: Frontiers in Artificial Intelligence and Applications. Proceedings of 4th Conference on Computational Models of Argument (COMMA 2012), vol 245, pp. 410-421.

Cap, P. 2013. Proximization: The pragmatics of symbolic distance crossing. Philadelphia: John Benjamins.

Debowska, K. 2007. The pragma-dialectical view of relatively 'naturalistic' discussions in Polish and English context. In: Proceedings of the 6th Conference of the International Society for the Study of Argumentation, pp. 307-315.

Debowska-Kozlowska, K. 2014. Processing topics from the beneficial cognitive model in partially and over-successful persuasion dialogues. In Argumentation, special issue "The Polish School of Argumentation”, eds. K. Budzynska and M. Koszowy, Vol. 3. doi:10.1007/s10503-014-9323-5.

van Eemeren, F., and R. Grootendorst. 1989. Speech act conditions as tools for reconstructing argumentative discourse. Argumentation 3(4): 367-383.

Gazdar, G. 1981. Speech act assignment. Cambridge: Cambridge University Press.

Goodwin, J. 2014. Conceptions of speech acts in the theory and practice of argumentation: A case study of a debate about advocating. In Studies in Logic, Grammar and Rhetoric, special issue of the argumentation series on Pragmatics and Dialectics of Argument, vol. 36(49), eds. Budzynska, K., F. van Eemeren, and M. Koszowy. Berlin: De Gruyter.

Koszowy, M., and M. Araszkiewicz. 2014. The Lvov-Warsaw School as a source of inspiration for argumentation theory. In Argumentation, special issue "The Polish School of Argumentation", eds. K. Budzynska and M. Koszowy, Vol. 3. doi:10.1007/s10503-014-9321-7.

Lewis, D. 1979. Scorekeeping in a language game. Journal of Philosophical Logic 8: 339-359.

Reed, C., and M. Koszowy. 2011. The development of argument and computation and its roots in the Lvov-Warsaw School. In Studies in Logic, Grammar and Rhetoric, special issue of the argumentation series on Argument and Computation, ed. Koszowy, M. 23(36):15-37. 
Sbisà, M. 2002. Speech acts in context. Language and Communication 22: 421-436.

Searle, J. 1969. Speech acts: An essay in the philosophy of language. New York: Cambridge University Press.

Searle, J. 1979. Expression and meaning: Studies in the theory of speech acts. Cambridge: Cambridge University Press.

Searle, J. 2010. Making the social world: The structure of human civilzation. Oxford: Oxford University Press.

Snoeck-Henkemans, A.F. 2014. Speech act theory and the study of argumentation. In Studies in Logic, Grammar and Rhetoric, special issue of the argumentation series on Pragmatics and Dialectics of Argument, vol. 36(49), eds. Budzynska, K., F. van Eemeren, and M. Koszowy. Berlin: De Gruyter.

Strawson, P. 1964. Convention and intention in speech acts. Philosophical Review 73: 439-460.

Walton, D. 1998. Ad hominem arguments. Tuscaloosa: University of Alabama Press.

Walton, D. 2000. Scare tactics: Arguments that appeal to fear and threats. Berlin: Kluwer Academic Publishers.

Walton, D.N. 2008. Informal logic: A pragmatic approach, 2nd ed. Cambridge: Cambridge University Press.

Witek, M. 2013a. How to establish authority with words. In Theory of imperatives from different points of view, vol 2, eds. Brozek, A. et al., pp. 145-157. Warszawa: Semper.

Witek, M. 2013b. Three approaches to the study of speech acts. Dialogue and Universalism 23(1): $129-142$.

Załęska, M. 2011. Ad hominem in the criticisms of expert argumentation. In Proceedings of the 7th conference of the International Society for the Study of Argumentation, eds. van Eemeren F.H., B. Garssen, D. Godden, and G. Mitchell, pp. 2047-2057. Amsterdam: Sic Sat. 